\title{
The New Hybrid Method for Vulnerability Assessment in Floodplain Area due to Dam Break
}

\author{
Mohammad Ali Nekooie ${ }^{1}$ and Saeed Gholizadeh ${ }^{1}$ \\ ${ }^{1}$ Malek-Ashtar University of Technology
}

September 25, 2021

\begin{abstract}
Despite all the importance of dams, dam failure, always threatens downstream areas by both natural and man-made sources and caused great human and financial losses. Vulnerability analysis is one of the main assessments to achieve a risk map and help policymakers reduce the losses and consequences of the failure. Therefore, this study aims to develop a new integrated hybrid model based on the security vulnerability assessment (SVA) and hydraulic analysis of flood and Source-Pathway-ReceptorConsequences (SPRC) approach. For SVA forms, data were collected by questionnaires survey, and for flood mapping, the open-source software, HEC-RAS was used. Geographical Information System (GIS) was applied to a combination of layers based on the SPRC approach. Five different scenarios were modeled to obtain the flood map due to a dam break. Then, the output data from the HEC-RAS software were transferred to the GIS software to be merged with other data achieved from the survey based on the SVA approach. Finally, the risk map for a case study was developed by this new hybrid approach. The results of the modeling showed that the highest vulnerability was achieved by residential areas and the lowest vulnerability is achieved by agricultural land due to floods by the dam failure.
\end{abstract}

\section{Introduction}

Dams are defined as an artificial obstruction to natural flows, which helps to accumulate water for agricultural reasons and energy generation, potable water supply, flood mitigation, and also recreational reasons (ICOLD, 2008). On the other hand, dams are mentioned as one of the key assets in the Critical Infrastructures and Key Resources (CIKRs) by the Department of Homeland Security (DHS) in the United States. There was a huge initiative from the federal government to coordinate a set of resilience and protection plans series, started the process of understanding what features create resilience in CIKRs (Gopalakrishnan \& Peeta, 2010). Due to this mission, dams and their environment should be designed for a safer, more secure, and more resilient domination by preventing, deterring, neutralizing, or mitigating the effects of deliberate efforts by terrorists to destroy, incapacitates, or exploits their elements (Fisher et al., 2010). There are also other programs for the protection of critical infrastructures such as the Swiss Federal program for critical infrastructure protection (CIP) to analyze its threats and identify vulnerabilities and assessing risks.

In principle, to assess the risk and provide the protection plan for dams and their downstream areas all relevant hazards and threats must be considered. The risks or vulnerabilities related to dams often refer to natural hazards such as earthquakes or floods or other technological failures. On the other hand, the spectrum of hazards and threats can be of many-sided nature, either technology- or human-related, natural and operational as well as contextual, which should be considered while the vulnerability of infrastructures should be assessed. Most of the researches in the last decades focuses on the natural hazards threats spectrum. However, the emergence of terrorist groups such as Al-Qaeda and ISIS revived the idea of protection of human-related threats. The spectrum of human-related threats ranges from unintended errors to targeted 
malicious attacks, either physical (e.g., explosive devices) or cyber, which deal with sophisticated models capable of describing thought and ideology transposed to terror and destruction (Kröger \& Zio, 2011). Thus, risk assessment and vulnerability assessment should expand to all properties related to the dams from farms, transportation routes, energy lines, pipes, business areas, industries, cities or villages, and even biosphere assets. There are much research works on the loss of life and flood mortality highlighted by different models and frameworks especially developed by Jonkman and his teams (S. Jonkman \& Vrijling, 2008; S. Jonkman, Vrijling, \& Vrouwenvelder, 2008; S. B. Jonkman, Maaskant, Kolen, \& Needham, 2016; S. N. Jonkman, Maaskant, Boyd, \& Levitan, 2009). He divided different methods in loss estimation into three categories as macro-level by characterizing the event, Meso-level by characterizing the location, and finally micro-level by investigating the individuals (S. B. Jonkman et al., 2016). In the developed equation, the important property is people, and any risk number is calculated based on the number of people at risk and two reducing factors as sheltering fraction (Roozbahani, Zahraie, \& Tabesh) and evacuation fraction $\left(\mathrm{F}_{\mathrm{E}}\right)$ which is illustrated in eq.1. The mortality fraction is the other factor $\left(\mathrm{F}_{\mathrm{d}}\right)$ that has been used in other risk assessment equations (eq.2) where $\mathrm{N}$ is a number of people at risk and $\mathrm{N}_{\mathrm{PAR}}$ is the number of people at risk.

\begin{tabular}{ll}
\hline $\mathrm{N}_{\mathrm{EXP}}=\mathrm{N}_{\mathrm{PAR}}\left(1-\mathrm{F}_{\mathrm{E}}-\mathrm{F}_{\mathrm{S}}\right)(\mathrm{S} . \mathrm{N}$. Jonkman et al., 2009) & $(1)$ \\
\hline $\mathrm{N}=\mathrm{F}_{\mathrm{d}}\left(1-\mathrm{F}_{\mathrm{E}}\right) \mathrm{N}_{\mathrm{PAR}}$ (S. B. Jonkman et al., 2016) & $(2)$ \\
\hline
\end{tabular}

The other approach for estimation flood mortality risk is the US army corps of engineers scalable approach, which is based on three factors of flood severity, exposed population, and shelter type (Needham, Fields, \& Lehman, 2016). Penning-Rowsell et al., in 2004 introduced a framework for risk assessment while they want to estimate injury and loss of life. This framework contains four stages for risk assessment as Hazard identification, Hazard characterization, Exposure Assessment, and Risk Characterization. However, the foundation of hazards in this study is also based on natural hazards (Penning-Rowsell, Floyd, Ramsbottom, \& Surendran, 2005).

It is very important to identify parameters related to the flood risk due to breaking dams, especially by malicious attacks. In the dam failure risk assessment model mostly the dominant failure mode of the dam is identified. There are different parameters, which are mentioned in another research for evaluating and assessing the vulnerabilities due to a dam break. The speed of onset, flood duration, type of debris, nature of floodwater, level of flood risk, nature of floodplain which dictates water depth, and velocity are some of these parameters mentioned in previous research (Aerts, 2016; Delgado-Hernández, Morales-Nápoles, DeLeón-Escobedo, \& Arteaga-Arcos, 2014; Matos, Mignan, \& Schleiss, 2015; Penning-Rowsell et al., 2005; Somos-Valenzuela et al., 2015; Sun et al., 2014; Tsakiris, 2014; Zhang, Xu, Liu, \& Peng, 2013). Vulnerability assessment has been computed based on consequences in three categories by Sun et al. in 2014 as life loss, economic loss, and social and environmental impact, although the speed and depth of flow downstream have been considered in dam-break flood simulation (Sun et al., 2014; Zhou et al., 2014). In other methods such as the GenMR framework for large dams, the hazard type is connected to damage classes for assessing vulnerability while considered hazards are more performances based on hydropower or outlet malfunction besides natural hazards such as flood and earthquake (Matos et al., 2015). Other researches assign the value of properties exposure to flood as a basic element for vulnerability assessment (Aerts, 2016). One of the comprehensive descriptions for the vulnerability was presented as a dependency, mainly on the degree of exposure, the capability of the system to withstand, the magnitude of the phenomenon, and the social factor (Tsakiris, 2014). In HURAM model also depth, speed, and duration are three important factors to estimate vulnerability to dam-break flood (Zhang et al., 2013). Figure 1 tries to illustrate the different vulnerability assessment parameters based on previous methods. 


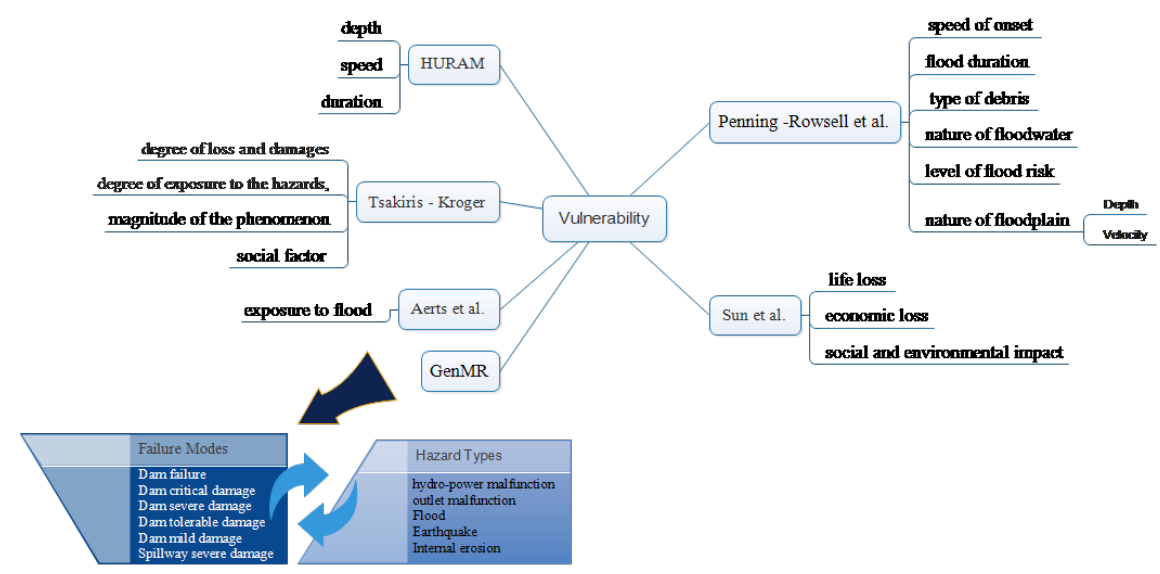

Figure 1: Different vulnerability assessment parameter based on previous research

Catastrophic losses in terms of human casualties, property destruction, economic damages, and loss of public confidence could result from dam failure in the downstream and floodplain area. Traditionally, when manmade disasters caused by sabotage or terrorist actions, the risk is expressed as a function of the likelihood of an initiating event, the likelihood of system failure, and the consequences associated with the failure. There are different models for assessing the risk of a variety of assets such as Sandia series as RAM models for dams (D-RAM), RAMCAP, Security Vulnerability Assessment (SVA), CARVER + Shock, PHA, RVA, What If, FMEA, FMECA, MSRAM, SRFT, and KSM. Some of these methods are qualitative or semi-qualitative, and some of them are quantitative such as FTA and ETA (Biringer, Matalucci, \& O'Connor, 2007; A. Doro-on, 2011; A. M. Doro-on, 2014; Hokstad, Utne, \& Vatn, 2012). Some of these risk approaches are completely qualitative based on causes and consequences such as What If, PHA, and FMEA. The models such as FMECA or CARVER + shock emphasize criticality and exposure to the hazard. Some of the other approaches have selective techniques, but the comprehensive module is based on probability and consequence analysis, vulnerability assessment, and finally risk assessment such as RVA. Some of the other approaches are based on assumed parameters, which are rigid but simply such as an SRFT method. Another important factor in risk assessment is attractiveness, which is more comprehensive than exposure to the hazard. KSM model emphasis on attractiveness and it is developed based on strategies od Khalid Sheikh Mohamad (the designer of the 11 September attack). However, the other approach which covers threat analysis, asset analysis, attractiveness, and vulnerability assessment to achieve the risk number for each property is SVA. SVA is one of the comprehensive approaches, which is currently used in different sectors and infrastructures. One of the advantages of SVA is the flexibility of techniques that can be used in each part of SVA (Norman, 2016; van Staalduinen, Khan, \& Gadag, 2016).

Dams as one of the superstructures are very important infrastructures of each country, especially while dams are dominant to the crowded areas to make the high-potential target for terrorist action (Danso-Amoako, Scholz, Kalimeris, Yang, \& Shao, 2012). For instance, the Mosul dam which is the largest dam in Iraq became one of the tools of ISIS for threatening downstream cities during Mosul occupancy in 2016. On the other hand, dams have several advantages such as supplying water resources for potable water, agricultural activities, producing electricity, and controlling floodwaters. Thus, dams make the downstream area a growing population center inherently. Cities, industries, and farms start to grow up while environmental resources such as trees and woods are started to vanish. These factors highlight the vulnerability assessment and importance of risk analysis for dams especially based on downstream properties and assets. Several studies have been done in vulnerability assessment of areas that are under the effects of a flood caused by dam destruction. Messervey (2007) has created a framework and discovered modeling technique's methods for dam destruction. Awal (2008) studied dam destruction caused by landslide and flyover increasing water height (Awal, 2008) and other studies described different alternative signals and decreasing floodwater risk 
(Persson, 2015).

As it was considered, most of the researches in this field tried to zone floodwater and the level of flooding in downstream areas caused by through the dam destruction, by using hydraulic software or crisis management under natural threats (such as earthquake, floodwater and...), but there isn't any research to evaluate the accurate vulnerability of dam destruction assets based on hydraulic modeling in collaboration with water flow factors and destruction scenarios, particularly under man-made threat. Vulnerability assessment on infrastructures becomes a highlighted and suspected approach from homeland security agencies and even private sectors, which owned infrastructures or at least be one of the stockholders of that infrastructures. Vulnerability assessment is a part of risk assessment, which shows the dam or any investigated infrastructure how vulnerable to the identified threat. So, the vulnerability of infrastructure could be separated into three categories, which show the enhancement of three generations of assessment. In the first generation which is clear from early models such as FMEA, CORVER, RVA, etc.; the inherent properties of an asset become the main nutrition for assessment of vulnerability or even the risk assessment of the asset. In the next generation while the KSM method or SRFT considered the attractiveness and exposure to the hazard as the other main criterion of vulnerability, which was mentioned by Kröger and Zio (2011) too, besides asset property according to the vulnerability and risk analysis (Norman, 2016). Finally, the third generation is a triangulated approach based on asset property, attractiveness and dependencies, and interdependencies following the network of properties. Model-Based Risk Assessment (MBRA) is one of the integrated models developed by Lewis and Al Mannai in 2008 under third-generation (Mannai, 2008). The security Vulnerability Assessment (SVA) approach also considered attractiveness beside the criticality of properties. However, there is a necessity for a more scientific approach especially on behalf of hydraulic characteristics of flood and interaction between flood and downstream properties in the floodplain area while the destructive action is succeeded.

So, based on the latest vulnerability assessment generation a new hybrid approach should be developed that considers the vulnerability of the dam's downstream area. Thus, this research aims to modify an integrated hybrid model to analyze the vulnerability of dam's downstream assets due to man-made succeeded adversary threats to provide risk analysis and management and plan for protection or mitigation of the high-risk area. Figure 2 is showing the theoretical framework of this approach. 


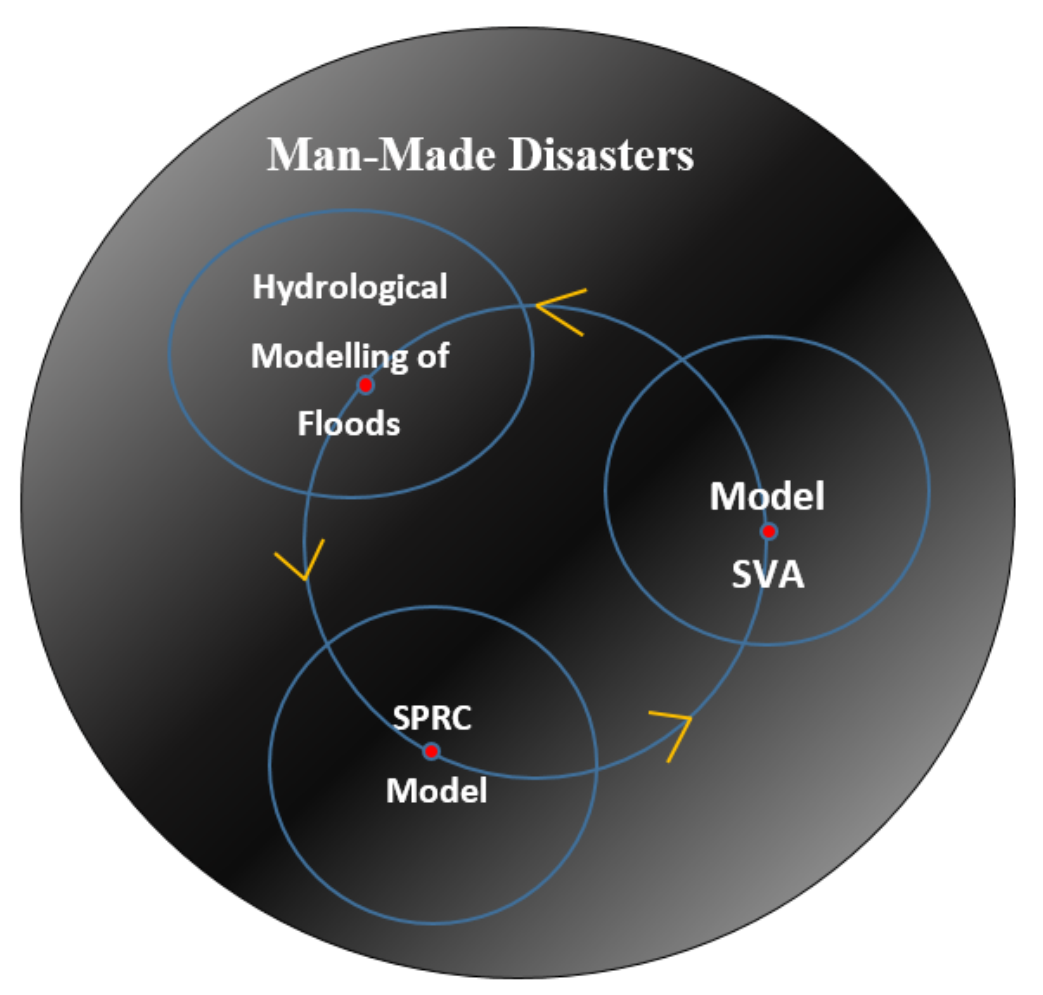

Figure 2:The new hybrid approach for vulnerability assessment

\section{Methodology}

As it was mentioned in early statements, it is advisable to generate a new approach with the combination of security risk modeling consist of inherent characteristics of assets and their attractiveness with hydraulic and hydrological characteristics of flood and floodplain area in contact with downstream assets. Thus, the parallel approach is needed to provide appropriate risk analysis steps besides flood mapping and horological analysis. As illustrated in Figure 3, the task of risk analysis is carried out by performing a modified SVA method. On the other hand, the hydraulic model is developed by HEC-RAS to extract the vulnerable factors of flood risk as to the height and velocity of water flow. Then, the SPRC method is applied as a connection bridge between these two parallel calculations to finalize the risk map based on the Geographical Information System (GIS). Figure 3 is illustrating the models and tools according to this research. 


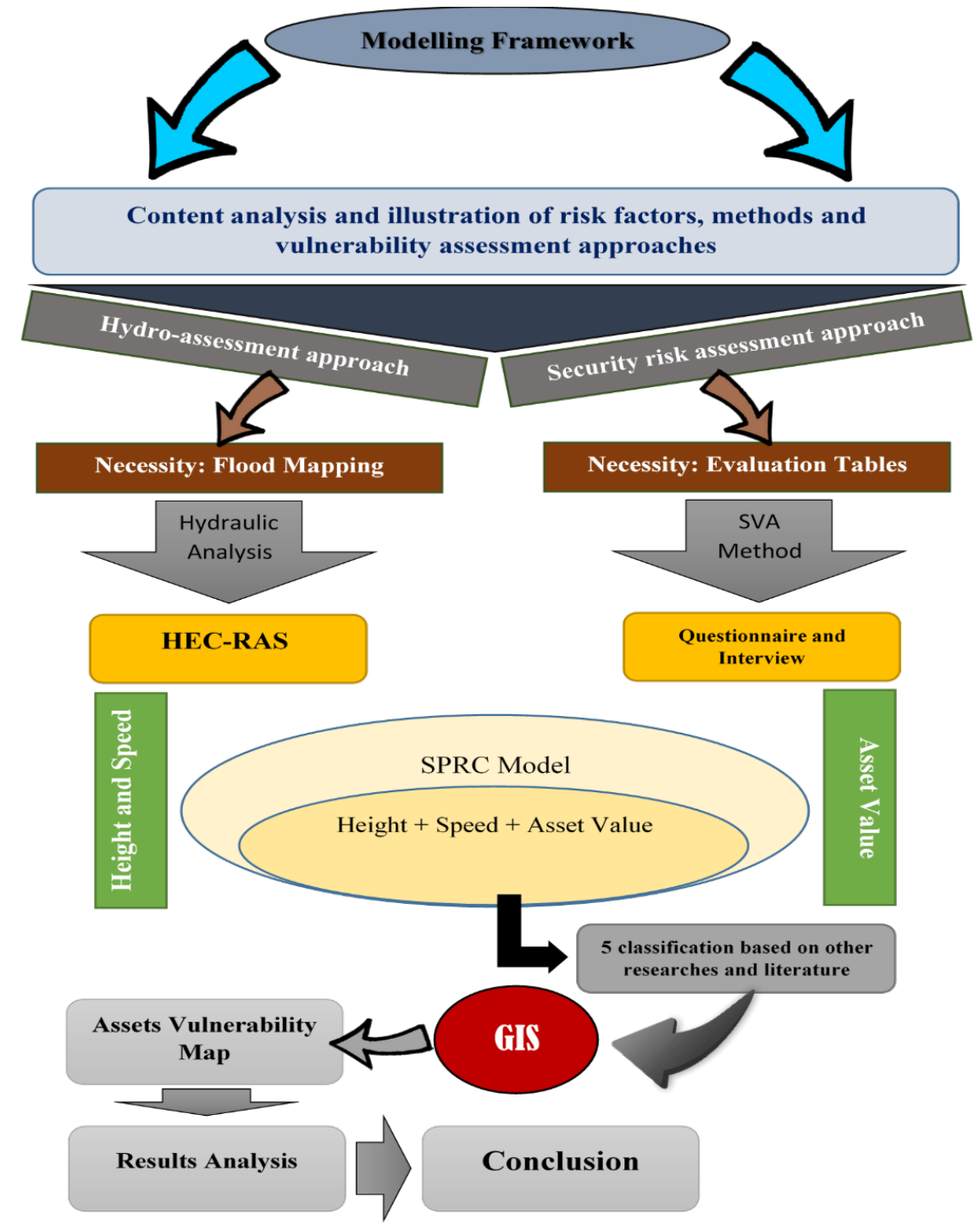

Figure 3: The process of research

\subsection{SVA model}

Dams and their facilities are assigned as critical infrastructures and key assets. Thus, the Risk assessment model should consider the attractiveness of facilities and probability of occurring a threat while the vulnerability due to each type of threat should be considered simultaneously. The Security Vulnerability Assessment (SVA) method is considered as a basic model for risk assessment in this study. Ranking in the SVA method includes a 5-level Likert scale that is classified with a query according to the experts' suggestions. Level one of the assets shows the minimum value and level five shows the maximum (van Staalduinen et al., 2016). Figure 4 shows the 5-level solution SVA methodology. 


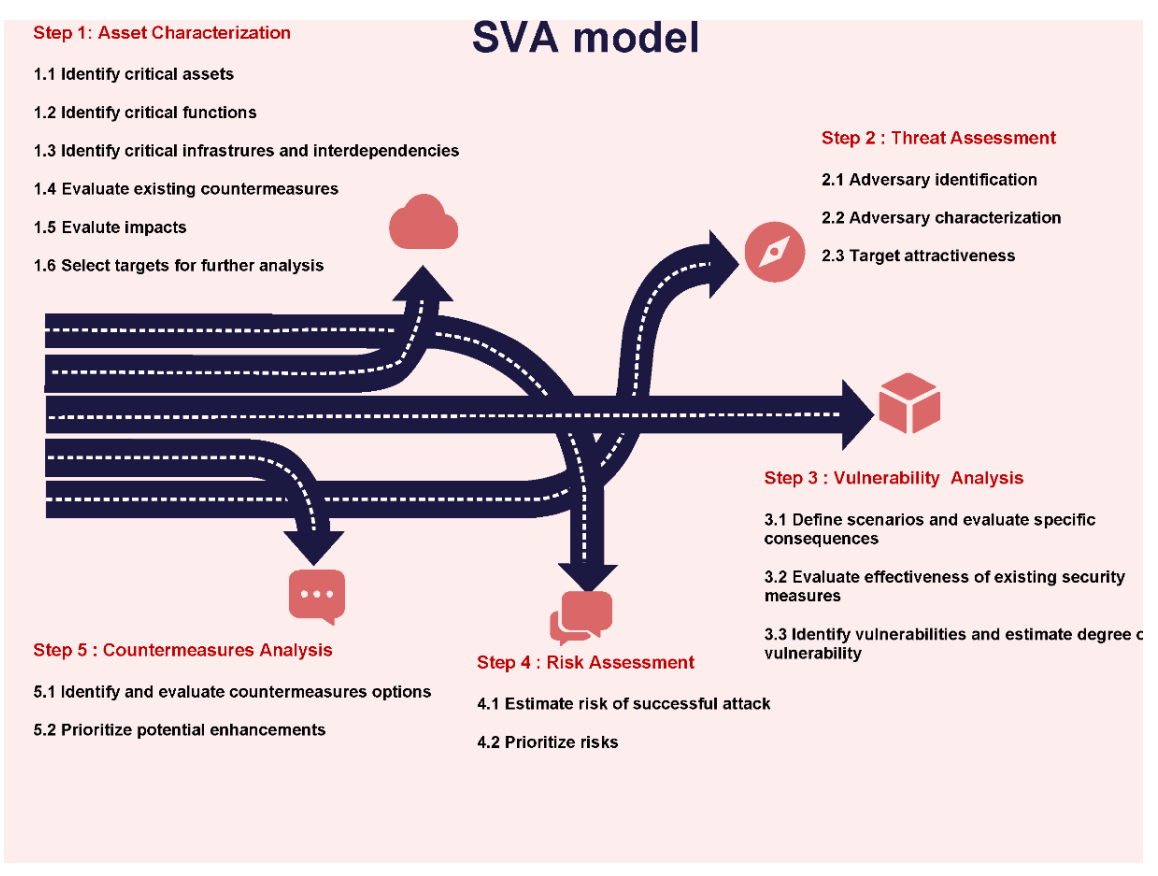

Figure 4: SVA model

\subsection{SPRC model}

It is important to identify a clear platform for connecting security risk assessment to the engineering approach for vulnerability assessment. The conceptual Source-Pathway-Receptor-Consequence-Model (SPRC-Model) was proposed in 2001. It shows a simple causal chain ranging from the basic sources of danger (sources) through the links and lines of interactions (pathways) which make impacts on elements at risk (receptors) and finally assess the effects of disasters on receptors (consequences) (Schanze, 2006). The SPRC method is a conceptual method to evaluate vulnerability and the risk of floodwater, vulnerability, and risk assets against floodwater occurrence can be estimated and measured. Figures 5 and 6 show the process of this methodology. As illustrated in figure 5, the interaction between assets and source of danger plays an important role while it is defined as pathways. 


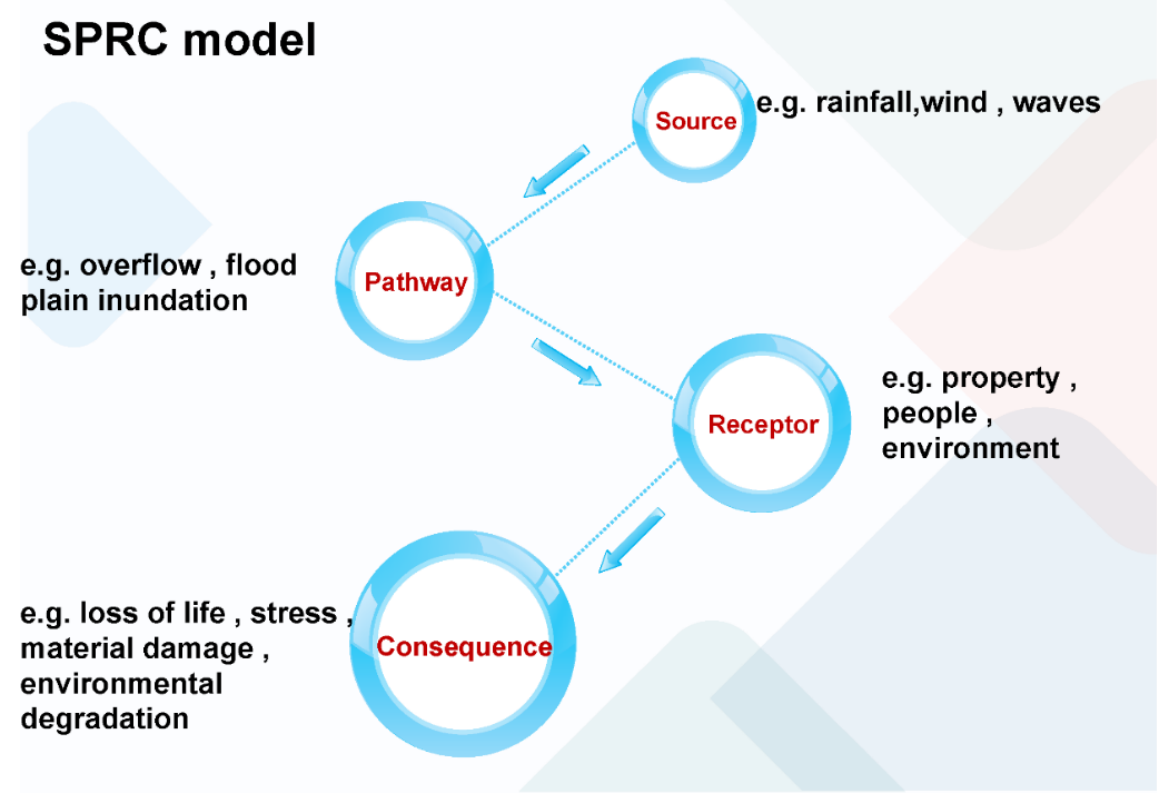

Figure 5: SPRC model

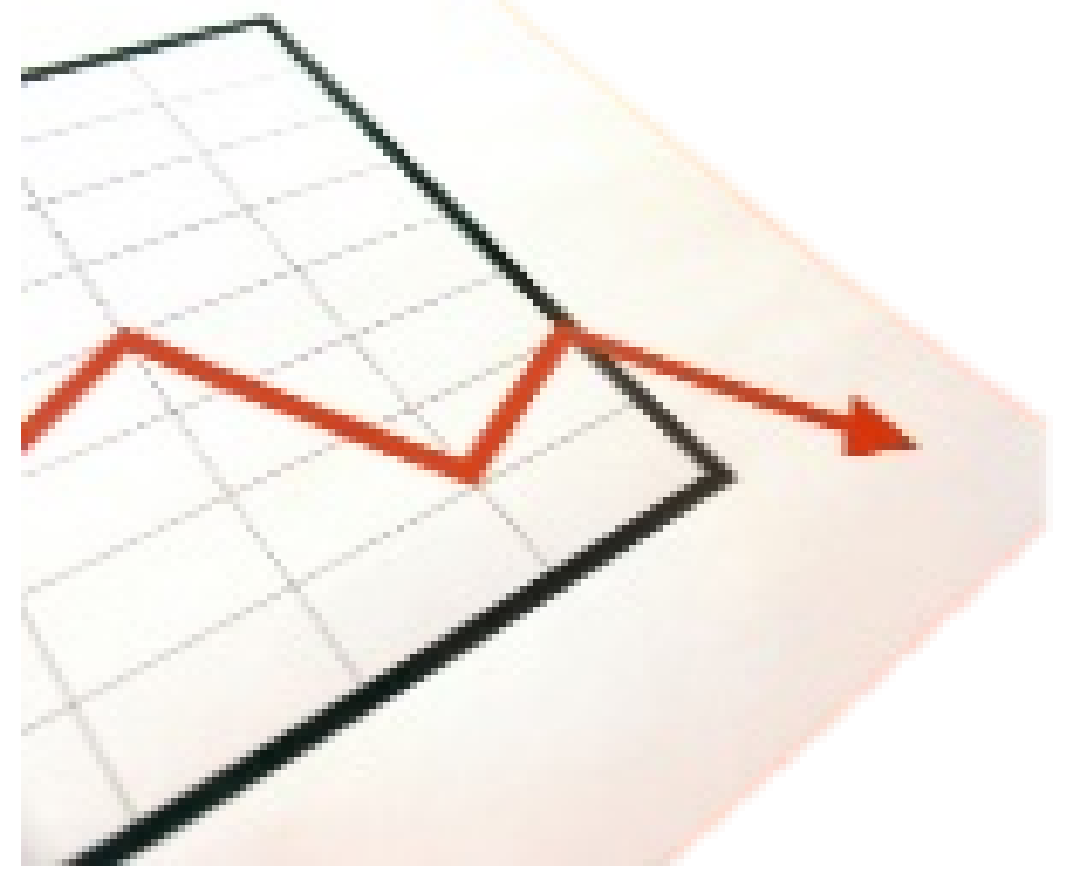

\subsection{Flood Mapping Model}

One of the important criteria for risk assessment is vulnerability, which was calculated in SVA by the qualitative approach. This study tries to make the combination of the vulnerability of assets with the source of danger, which is a flood due to dam destruction. Thus, it is necessary to assume different scenarios for the dam break due to terrorist attacks and obtaining outputs. The outputs of the breaking dam were used for 
simulating the flood loaded on downstream lands to obtain the flood mapping, including the cross-section and velocity of the flood in the downstream floodplain area. Using HEC-RAS as open-source software that is compatible with GIS provides advantages to merge data from security sources with hydraulic and flood data. This software also allows designing culverts, bridges, side weirs, spillways even if necessary while the countermeasures are provided.

To model the flow of the flood, the boundary conditions should be introduced to HEC-RAS software. Boundary conditions (B.C) include upstream and downstream B.Cs that contain a certain flow rate and water surface balance, or water surface ramp (angel) and critical depth. Figure 7 demonstrates the simulation processes of flood mapping in HEC-RAS software and the transition of outputs to GIS.

\subsection{Vulnerability modeling in GIS}

Previously in the typical SVA model, the vulnerability assessment was determined based on questionnaire results. However, the SPRC model suggested the measurement of vulnerability caused by the flood by velocity, water level, and value (sensitivity) of an asset (Receptor sensitivity). According to Table 1, the factors used in asset vulnerability with similar studies are classified into five classes (Likert scales). The information layers are prepared numerically according to the factors. Then layers (height, velocity, and assets value) have been multiplied and integrated with GIS employing Spatial Analyst tools and Raster Calculator sub-menu to obtain an asset vulnerability final map (figure 8).

Table 1: Classification indices to determine the vulnerability

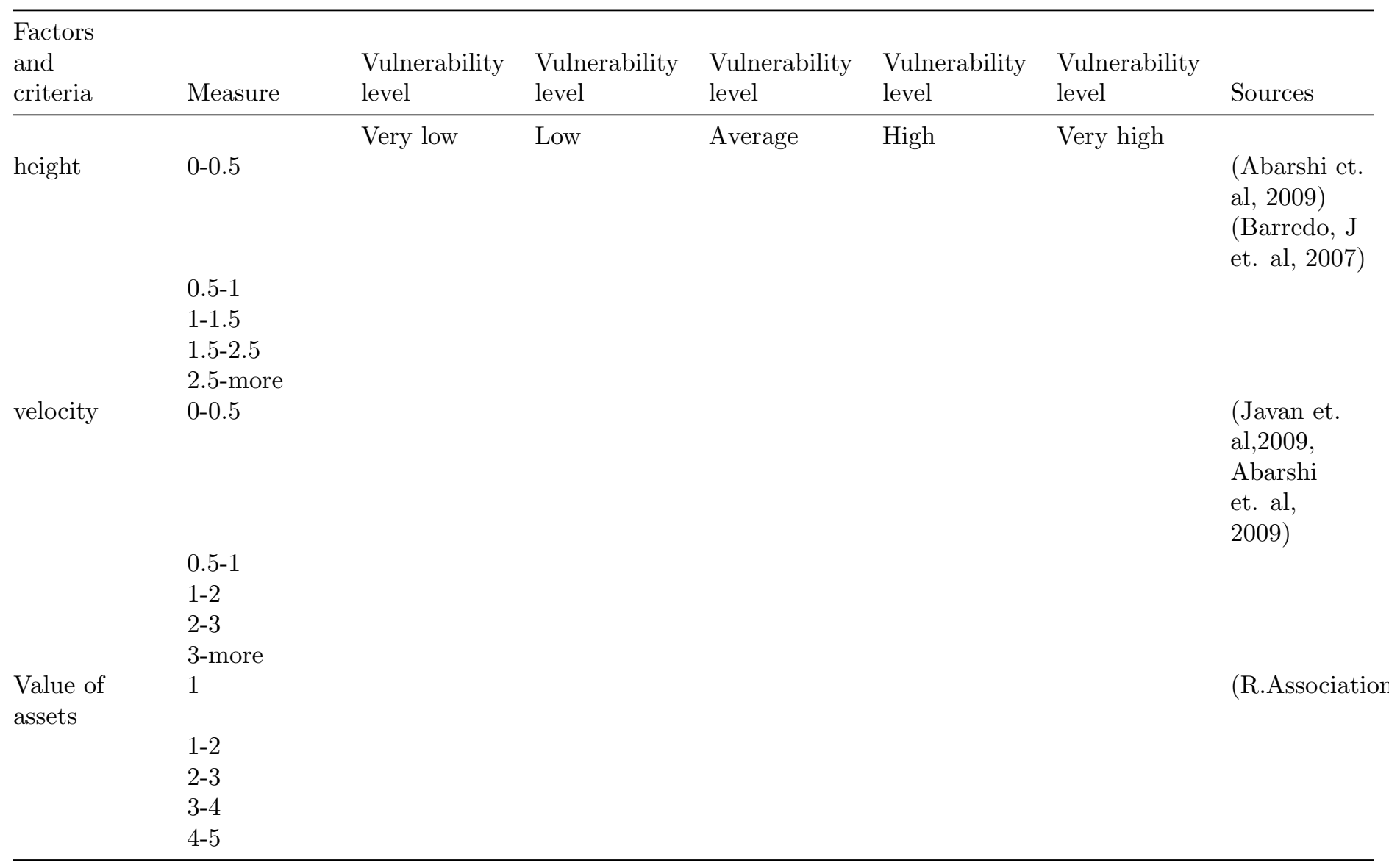




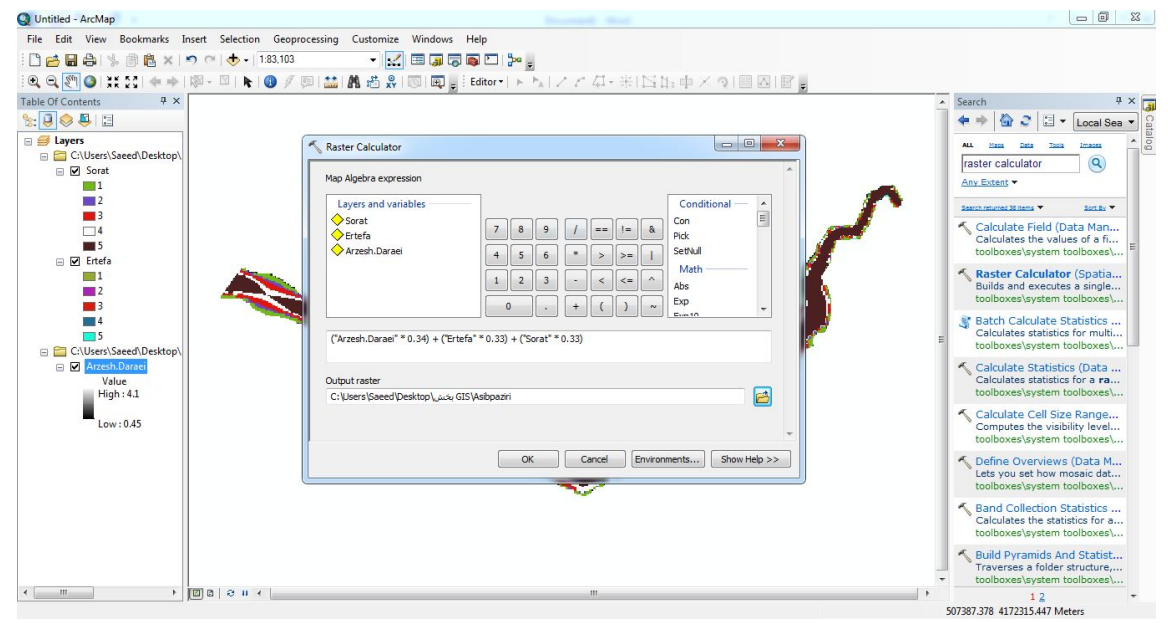

Figure 8: Method of layers' overlap and integration

To illustrate the application of this method, a conceptual earth dam is studied in this research. Table 2 illustrates the characteristics of the dam which is an earth dam with a clay core. The height of the dam is assumed at $60 \mathrm{~m}$, and other characteristics are assumed as follows.

Table 2: Earth dam characteristics

\begin{tabular}{ll}
\hline Dam name & Case Study 1 \\
\hline Dam type & Soil with a clay core \\
Dam height & $60 \mathrm{~m}$ \\
Crest length & $450 \mathrm{~m}$ \\
Crest width & $10 \mathrm{~m}$ \\
Reservoir water volume & $64,500,000 \mathrm{~m}^{3}$ \\
Free overflow valve & $1700 \mathrm{~m}^{3} / \mathrm{s}^{3}$ \\
Allocation for drinking water (neighbor city) & $18,000,000 \mathrm{~m}^{3}$ \\
Allocation for industry & $5,000,000 \mathrm{~m}^{3}$ \\
Irrigated lands & $5700 \mathrm{Hectare}$ \\
The capacity of the bottom outlet & $26.7 \mathrm{~m}^{3} / \mathrm{s}$ \\
\hline
\end{tabular}

In the next part, it is necessary to define the downstream assets which could be affected by the flood due to dam destruction. Table 3 shows tangible assets according to experts.

Table 3: downstream assets

\begin{tabular}{lll}
\hline No. & Assets name & Nature of assets \\
\hline 1 & Settlements areas & Physical \\
2 & Farms & Physical \\
3 & Infrastructure installation & Physical \\
4 & environmental & Physical \\
5 & Human force and population centers & Human \\
\hline
\end{tabular}

\subsection{Questionnaire survey}

Based on the SVA method, different parts should be assessed by a questionnaire among experts in the era of 
security and dam safety. First of all, the threat should be assessed simultaneously with property assessment. Then the combination of these factors with attractiveness gives the criticality of properties. The consequence is achieved based on the SVA approach. Thus the questionnaires are developed based on four main goals. First is the evaluation of asset values based on the vision of the expert. Secondly, it tried to rank threats, and sequentially investigated the attractiveness of the assets. Finally, the questionnaires help the researchers to rank the probable consequences. Table 4 illustrates these goals with related criteria accordingly. 79 experts work in the field of dam security which 50 of them answered the questionnaires. For the reliability of the questionnaire, the Cronbach Alpha was assessed, which was equal to 0.83. The result showed that the reliability of the questionnaire is in the appropriate range.

Table 4: Goals of the questionnaires

\begin{tabular}{lll}
\hline Sections & Goals $^{6}$ & Criteria \\
\hline 1 & Evaluation of asset values & Importance and Hazards \\
2 & Ranking the threats & Resources, History, current countermeasures, capability and motivation of e \\
3 & The attractiveness of the assets & Destruction, failures, and consequences \\
4 & ranking the probable consequences & Casualties, Damages, Environmental side effects \\
\hline
\end{tabular}

\section{Results and discussion}

\subsection{SVA Assessment Based on Questionnaire Survey}

As mentioned previously, first of all, it is necessary to assess the main parts of SVA based on its procedure regarding the questionnaire survey. Accordingly, asset vulnerability for dam destruction scenarios on the downstream side is obtained and analyzed. As illustrated in table 5, downstream dwellers have the maximum and environmental properties have the minimum value in the asset value-determination process.

Table 5: Assets priority in terms of value

Assets prioritization based on importance and perils

\begin{tabular}{ll}
\hline 5 & Dwellers (Human Resource) \\
4 & Residential Areas \\
3 & Infrastructures \\
2 & Farms \\
1 & Environmental Properties \\
\hline
\end{tabular}

The preliminary step is prioritizing threats. Based on the results of the questionnaire survey the terrorist attack and government-supported threats are considered the highest threat probability that may occur in this dam. Government-supported threats (wars or struggles between two countries) and dissatisfied employees are rated in second and third positions. Table 6 illustrates this ranking for the threats.

Table 6: Threat Prioritization in terms of occurrence

Threat Prioritization based on (threat sources and records, potential measures, enemy's ability and motive)

$4 \quad$ Internal and international terrorists

3 Adversary countries

2 Dissatisfied employees and employers

In the next step of SVA, according to Table 7, the results of the questionnaire illustrate that the adversary forces attracted to dwellers (Human Resource) infrastructures and residential areas equally and finally bio- 
logical asset (Farmlands and Environmental Assets) goes last in priority. The results of the attractiveness analysis show for these assets such as reservoir dams, the most important vulnerable related properties are the people who live near the dam or use the potable water from this asset. The other dependent infrastructures such as roads and residential area near the dam are also achieved the highest attractiveness rate among other properties as higher probable casualties are possible.

Table \%: Prioritizing assets in terms of target attractiveness

Assets prioritization based on (destructions, disorders, and consequences)

\begin{tabular}{ll}
\hline 3 & Dwellers (Human Resource) \\
3 & Infrastructures \\
3 & Residential areas \\
2 & Farmlands \\
1 & Environmental \\
\hline
\end{tabular}

In the next part, the consequence of any successful adversary attack for each of the assets is evaluated. This evaluation is based on two parameters as casualties and estimated damages. Table 8 shows the results of the questionnaire on ranking consequences for each of the properties. The results of questionnaires show that dwellers (human resources) are ranked first. Infrastructures and residential areas achieved the highest rank. Then farmlands and environmental properties achieved similar rank according to their consequence level.

Table 8: prioritization of properties based on casualties, financial loss, and ecological effects

Assets prioritization based on (deaths, financial losses, and ecological effects)

\begin{tabular}{ll}
\hline 5 & Dwellers (Human Resource) \\
4 & Residential areas \\
3 & Infrastructures \\
2 & Farmlands \\
2 & Environmental \\
\hline
\end{tabular}

By finalizing this section, the primary step of the SVA method is accomplished. In the next step, the vulnerability should be determined based on flood modeling and different types of dam break scenarios.

\subsection{Flood modeling results due to dam failure scenarios}

In this part flood modeling outputs due to dam failure performed by HEC-RAS software are demonstrated as follows.

\subsubsection{Flood mapping, height, and speed of the flood}

The maximum flood hazard zone

The maximum flood hazard zone is $1309.82 \mathrm{~m}$ that occur in scenario 5 in the distance of $9026 \mathrm{~m}$ of the dam and 127 minutes after the dam fracture, presented in fig 9 . 


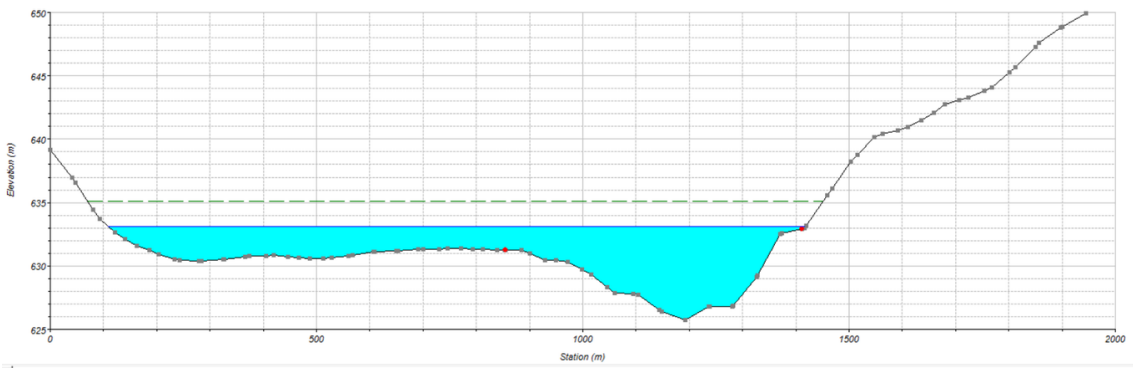

Figure 9: Cross-section of the maximum flood zone area

The maximum height of the flood

The maximum height of the flood is $11.248 \mathrm{~m}$ that occurs in scenario 5 in the distance of $2448 \mathrm{~m}$ of the dam and 115 minutes after fracture starting in the dam body, presented in Figure 10.

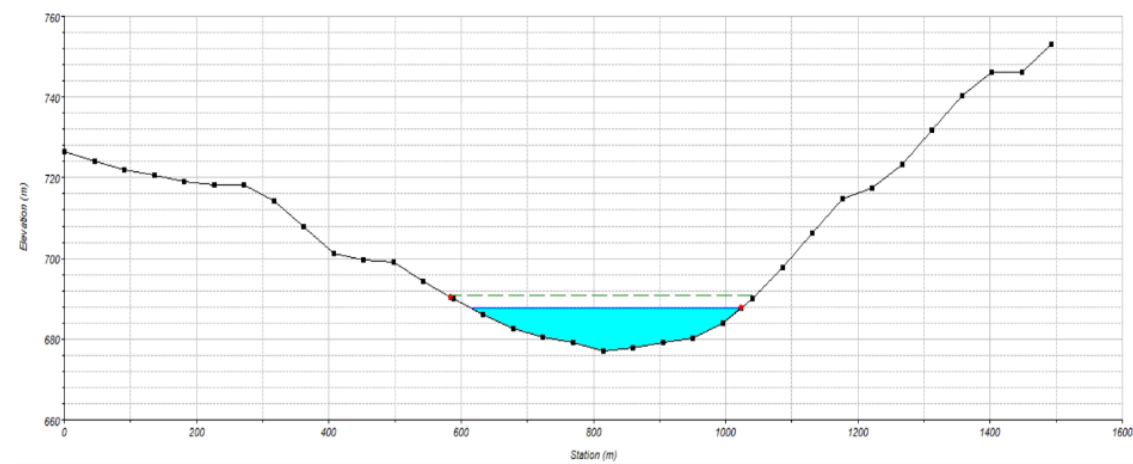

Figure 10: Cross-section of the maximum height of the flood

The maximum speed of the flood

The maximum speed of the flood is $11.248 \mathrm{~m} / \mathrm{s}$ that occur in scenario 5 in the distance of $2448 \mathrm{~m}$ of the dam and 115 minutes after fracture starting in the dam body, Figure 11 helps to calculate the speed of flood in this section.

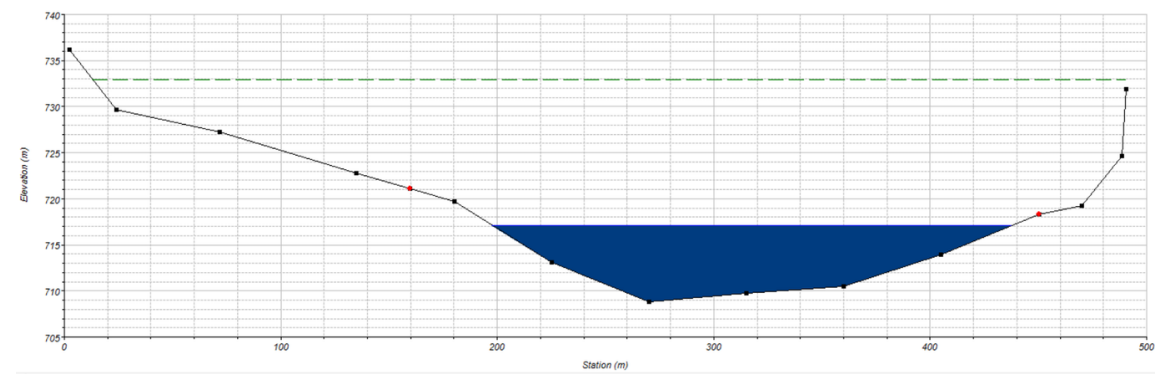

Figure 11: Cross-section of the flooded area with maximum speed

\subsubsection{Flood occurrence analysis in different scenarios}

The estimated Time of Arrival of the flood to residential areas and population centers can be extracted by HEC-RAS software. Table 9 demonstrates the arrival time of the flood to population centers. 
Table 9: Arrival time of the flood to population centers in scenarios in terms of minutes

\begin{tabular}{lll}
\hline Population center reach time (minutes) & Population center reach time (minutes) & Population center reach time (minutes) \\
\hline City 7 & City 6 & City 5 \\
205 & 190 & 156 \\
151 & 139 & 111 \\
123 & 112 & 88 \\
110 & 99 & 77 \\
103 & 93 & 72 \\
\hline
\end{tabular}

\subsection{Results of asset's vulnerability modeling in GIS}

Based on the classifications in Table 1 and application of each area and the results from HEC-RAS for Height, Velocity, and Value of the asset for each area in each scenario, the vulnerability estimated by multiplying them and integrating maps as a raster map where pixel's value shows the asset's vulnerability, so higher value in each pixel indicates higher vulnerability. Figures 12-16 show asset vulnerabilities based on the height, velocity, and value of each asset in different scenarios according to five classes.

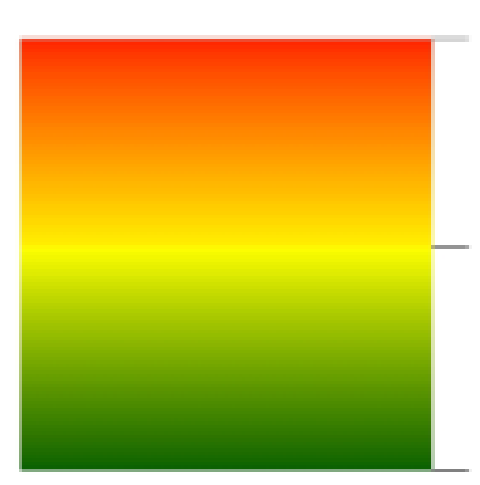

\section{High : 4.703}

\section{Low : 0.8185}

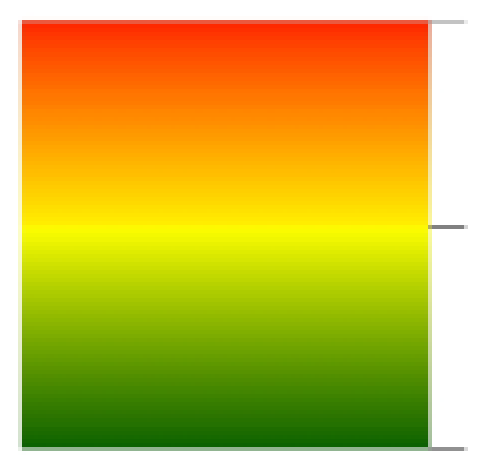

\section{High : 4.703}

\section{Low : 0.8185}




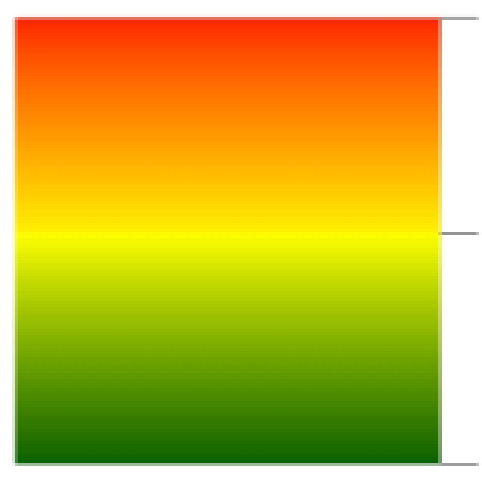

High : 4.703

Low : 0.967

High : 4.703

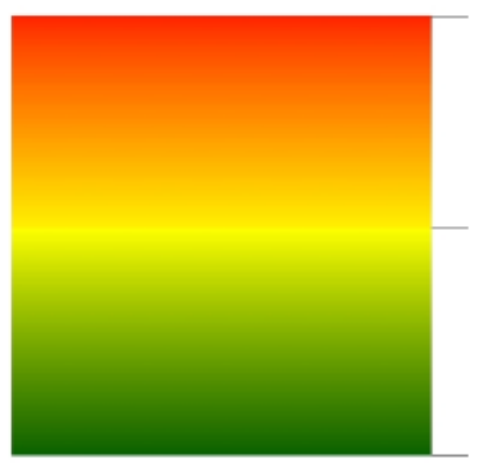

Low : 0.967

High : 4.703

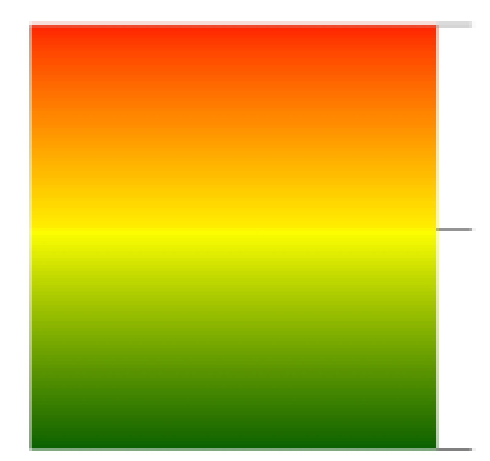

\section{Low : 0.8185}

3.3. Assets' risk modeling results in GIS 


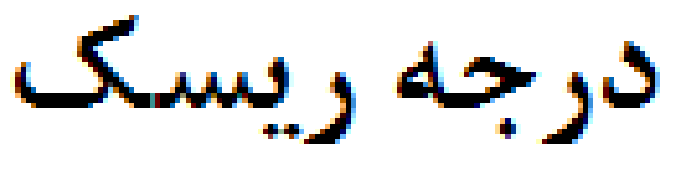

\section{Value}

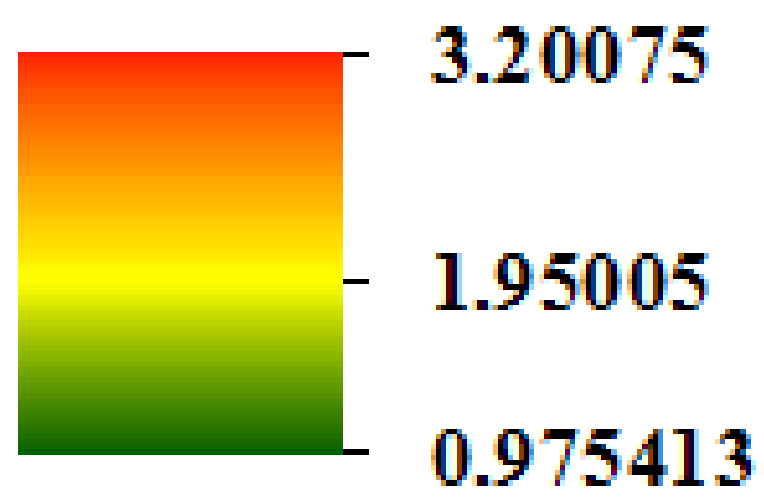

The risk map based on the SVA methodology is developed by multiplying vulnerability and likelihood from tables 5-8. The integrated risk map for each area is developed as raster maps where pixels value shows the risk for each asset and pixels with higher values achieved higher risk in each scenario. Figs 17 to 21 illustrate the risk of each downstream asset of the earth dam in each of the 5 scenarios. 


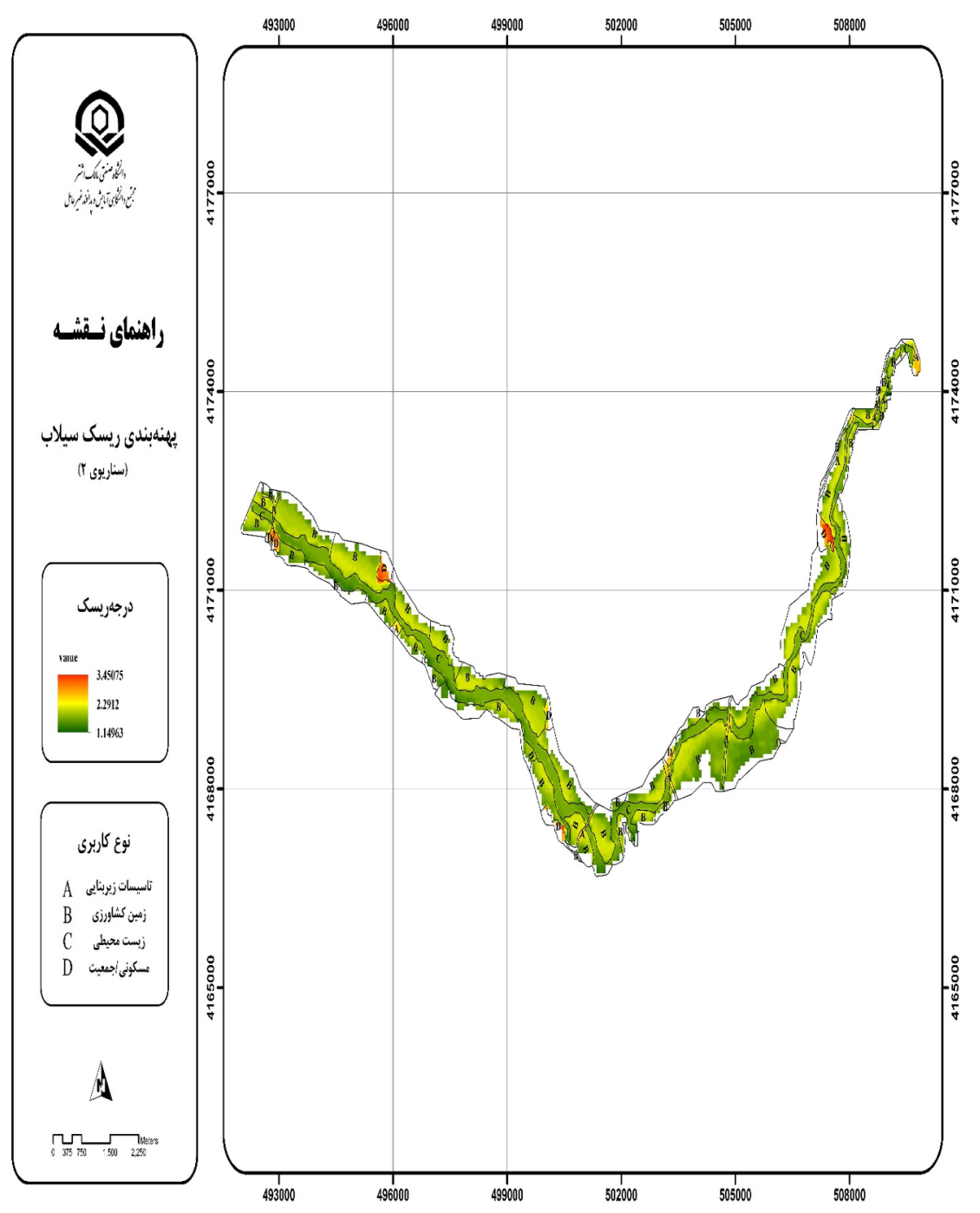



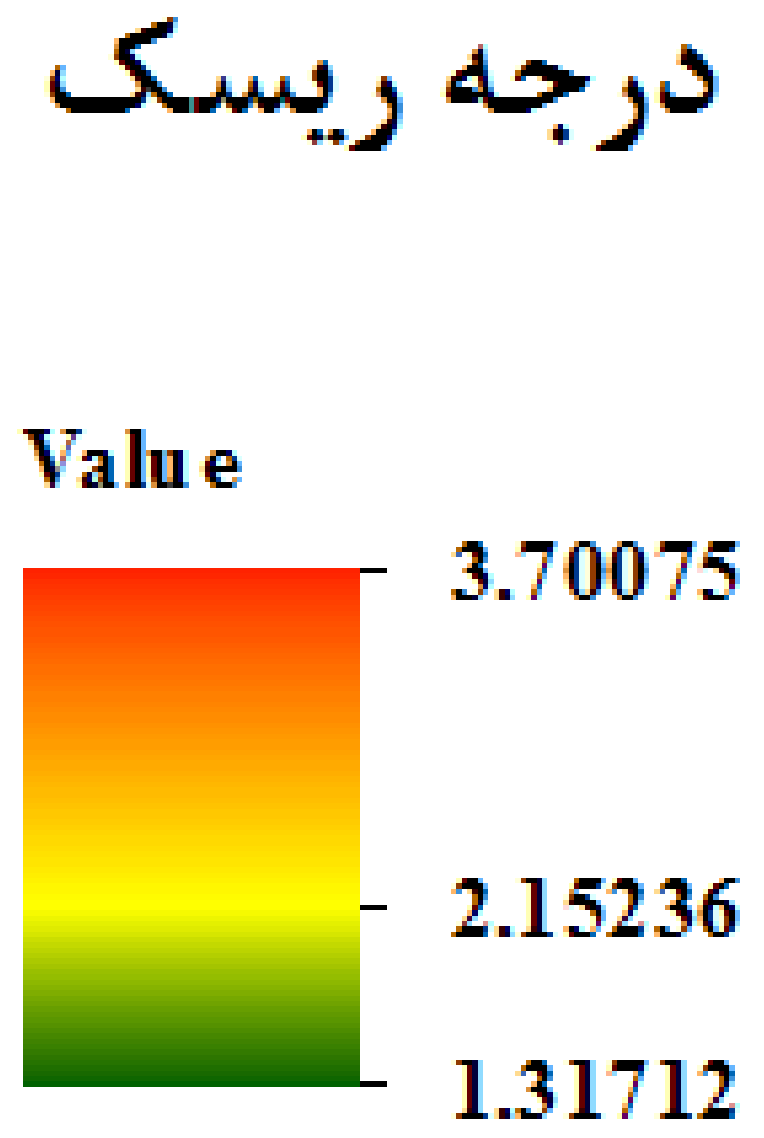

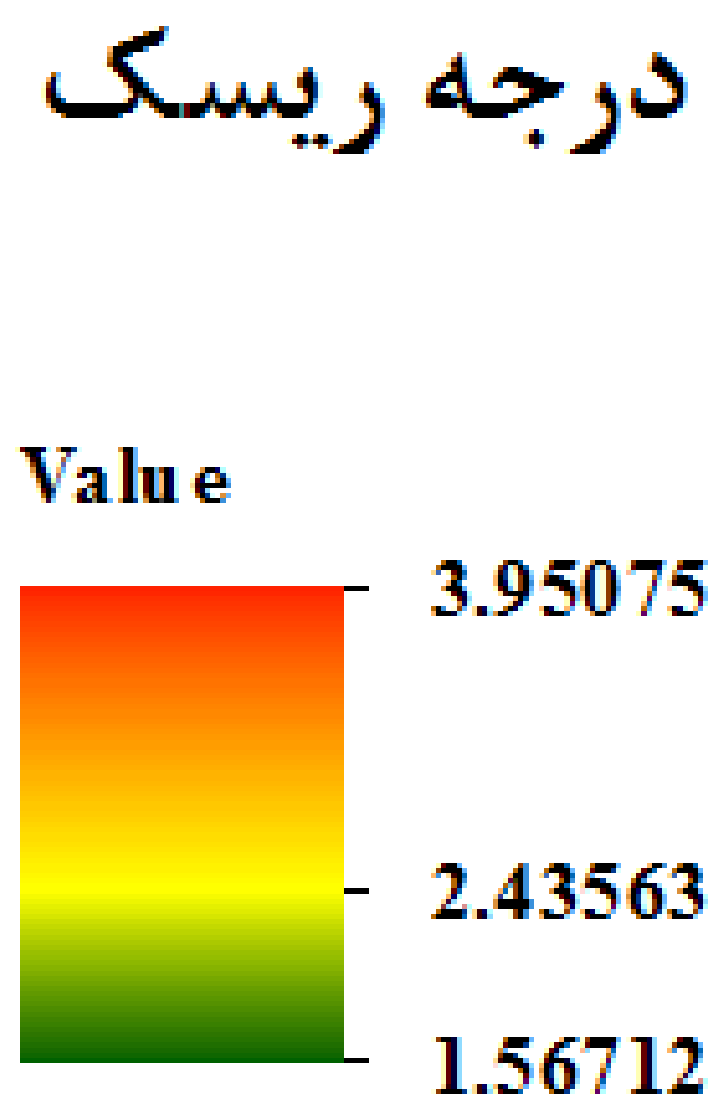

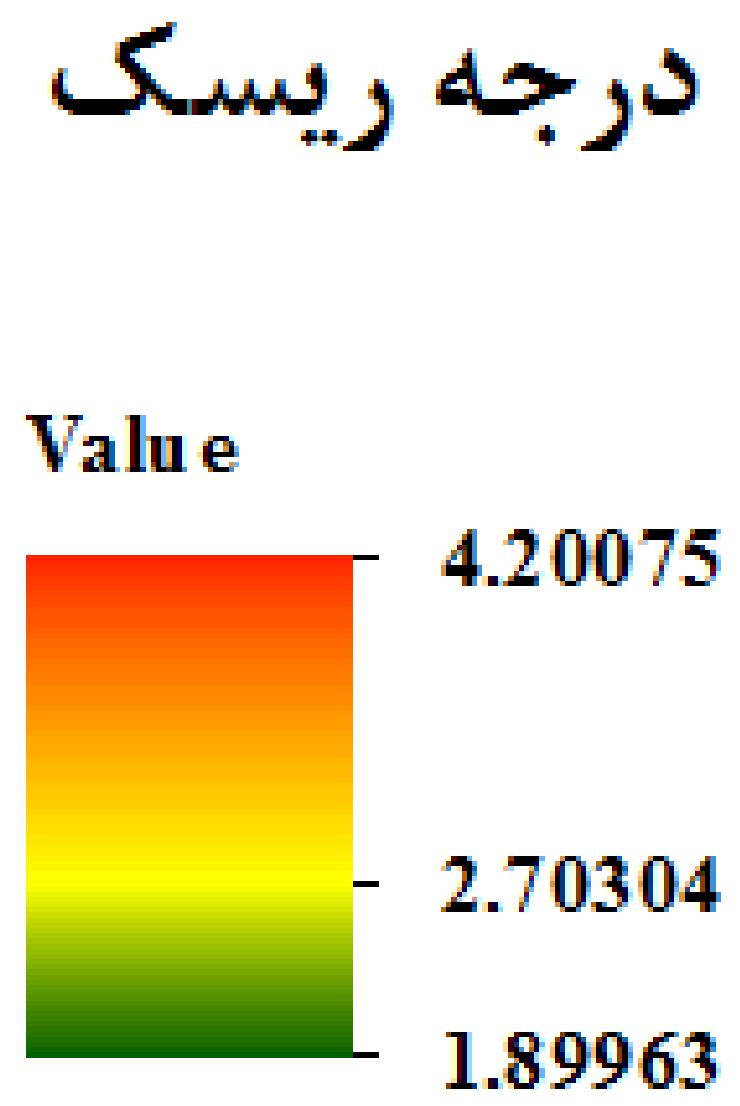

The high-risk areas are identified in each scenario where the risk-management approaches should be applied to them before other areas.

\section{Conclusion}

The occurrence of human threats such as military or terrorist attacks on dams cannot be completely restrained but losses and damages resulted from it can be reduced. The preliminary and most important step in reducing the risk of flooding due to the dam's break is assessing the risk for the downstream.

By achieving the risk, solutions to reduce the risk of downstream properties such as early warning or portable flood protection solutions to deal with this Phenomenon can be assigned for high-risk areas. This preparation should take place with a specific schedule and planning in different prospects of crisis management to reduce its damages. 
The new hybrid method for vulnerability assessment and risk analysis is developed in this study by the combination of security risk approaches and hydraulic of flood due to a dam break. Thus, the basic method for vulnerability and risk assessment is chosen as SVA, which is approved by EPA and API. Then for Vulnerability assessment, the HEC-RAS is employed for achieving velocity and height of flood and flood mapping due to the different scenarios of the flood. Finally, by using GIS, all elements of risk are introduced in different layers and by the integration of them, the risk map is achieved for each scenario. The most important results are met by applying in a case study as follows:

- Residential areas were considered the most valuable asset according to the result of the questionnaire using the SVA method.

- The terrorist action became the highest priority among other possible threats to the earth dam according to the questionnaire using the SVA method.

- Population centers were considered the highest priority in terms of consequences based on SVA and SPRC methods.

- The maximum height and speed of the flood are respectively $11 / 248 \mathrm{~m}$ and $17 / 63 \mathrm{~m} / \mathrm{s}$ related to scenario 5 that has been acquired by HEC-RAS software.

- The minimum arrival time of the flood to population centers is linked to city 1 for 10 minutes in scenario 5 and the maximum arrival time of the flood to population centers is linked to city 7 for 205 minutes in scenario 1.

- Risk modeling illustrates that farmlands achieved the lowest risk and population centers achieved the greatest risk number due to the flooding caused by dam break in the most dangerous scenario (scenario $5)$.

\section{Data Availability Statement}

Some or all data, models, or code generated or used during the study are available from the corresponding author by request (questionnaire, maps, vulnerability, and risk maps).

\section{Conflict of interest}

Authors of this research certify that, there is not any conflict of interest or use of third party resources which could be applied for this research. On behalf of all authors, the corresponding author states that there is no conflict of interest.

\section{References}

Aerts, J. C. (2016). Preface: Flood-risk analysis and integrated management. Natural Hazards and Earth System Sciences, 16 (4), 1005.

Awal, R. (2008). Study on landslide dam failure due to sliding and overtopping. (M.Sc.). University of Kyoto, Kyoto, Japan.

Biringer, B. E., Matalucci, R. V., \& O'Connor, S. L. (2007).Security Risk Assessment and Management: A professional practice guide for protecting buildings and infrastructures : John Wiley \& Sons.

Danso-Amoako, E., Scholz, M., Kalimeris, N., Yang, Q., \& Shao, J. (2012). Predicting dam failure risk for sustainable flood retention basins: A generic case study for the wider Greater Manchester area.Computers, Environment and Urban Systems, 36 (5), 423-433. 
Delgado-Hernández, D.-J., Morales-Nápoles, O., De-León-Escobedo, D., \& Arteaga-Arcos, J.-C. (2014). A continuous Bayesian network for earth dams' risk assessment: An application. Structure and Infrastructure Engineering, 10 (2), 225-238.

Doro-on, A. (2011). Risk assessment for water infrastructure safety and security : CRC Press.

Doro-on, A. M. (2014). Risk Assessment and Security for Pipelines, Tunnels, and Underground Rail and Transit Operations : CRC Press.

Fisher, R., Bassett, G., Buehring, W., Collins, M., Dickinson, D., Eaton, L., . . Lawlor, M. (2010). Constructing a resilience index for the enhanced critical infrastructure protection program . Retrieved from

Gopalakrishnan, K., \& Peeta, S. (2010). Sustainable and Resilient Critical Infrastructure Systems: Simulation, Modeling, and Intelligent Engineering . Chennai, India: Springer-Verlag Berlin Heidelberg.

Hokstad, P., Utne, I. B., \& Vatn, J. (2012). Risk and interdependencies in critical infrastructures. Chapters, $5,49-94$.

ICOLD. (2008). International Commission of Large Dams,ICOLD.Retrieved from

Jonkman, S., \& Vrijling, J. (2008). Loss of life due to floods. Journal of flood risk management, 1 (1), 43-56.

Jonkman, S., Vrijling, J., \& Vrouwenvelder, A. C. (2008). Methods for the estimation of loss of life due to floods: a literature review and a proposal for a new method. Natural Hazards, 46 (3), 353-389.

Jonkman, S. B., Maaskant, B. B., Kolen, B. B., \& Needham, J. J. (2016).Loss of life estimation-Review, developments and challenges.Paper presented at the E3S Web of Conferences.

Jonkman, S. N., Maaskant, B., Boyd, E., \& Levitan, M. L. (2009). Loss of life caused by the flooding of New Orleans after Hurricane Katrina: analysis of the relationship between flood characteristics and mortality. Risk analysis, 29 (5), 676-698.

Kröger, W., \& Zio, E. (2011). Vulnerable Systems . New York, USA: Springer

Mannai, A. (2008). Development of a decision support tool to inform resource allocation for critical infrastructure protection in homeland security. (PhD). Naval Postgraduate School Monterey, California, USA. (NSN 7540-01-280-5500)

Matos, J. P., Mignan, A., \& Schleiss, A. (2015). Vulnerability of large dams considering hazard interactions: conceptual application of the Generic Multi-Risk framework. Paper presented at the Proceedings of the 13th ICOLD Benchmark Workshop on the numerical analysis of dams, Lausanne, Switzerland.

Messervey, T. B. (2007). Integration of Structural Health Monitoring into the Design, Assessment, and Management of Civil Infrastructure. (Ph.D). University of Pavia, Pavia - Italy.

Needham, J., Fields, W., \& Lehman, W. (2016). The US Army Corps of Engineers Scalable Approach to Estimating Loss of Life from Flooding. Paper presented at the E3S Web of Conferences.

Norman, T. L. (2016). Risk analysis and security countermeasure selection : CRC press.

Penning-Rowsell, E., Floyd, P., Ramsbottom, D., \& Surendran, S. (2005). Estimating injury and loss of life in floods: a deterministic framework. Natural Hazards, 36 (1), 43-64.

Persson, E. (2015). Flood Warnings in a Risk Management Context : A Case of Swedish Municipalities. (phD Licentiate thesis, comprehensive summary). Karlstads universitet, Karlstad. Retrieved from http://urn.kb.se/resolve?urn=urn:nbn:se:kau:diva-35336 DiVA database.

Roozbahani, A., Zahraie, B., \& Tabesh, M. (2013). Integrated risk assessment of urban water supply systems from source to tap.Stochastic environmental research and risk assessment, 27 (4), 923-944. 
Schanze, J. (2006). FLOOD RISK MANAGEMENT - A BASIC FRAMEWORK. In J. Schanze, E. Zeman, \& J. Marsalek (Eds.), Flood Risk Management: Hazards, Vulnerability and Mitigation Measures (pp. 1-20). Dordrecht: Springer Netherlands.

Somos-Valenzuela, M., McKinney, D., Byers, A., Rounce, D., Portocarrero, C., \& Lamsal, D. (2015). Assessing downstream flood impacts due to a potential GLOF from Imja Tsho in Nepal. Hydrology and Earth System Sciences, 19 (3), 1401-1412.

Sun, R., Wang, X., Zhou, Z., Ao, X., Sun, X., \& Song, M. (2014). Study of the comprehensive risk analysis of dam-break flooding based on the numerical simulation of flood routing. Part I: model development.Natural Hazards, 73 (3), 1547.

Tsakiris, G. (2014). Flood risk assessment: concepts, modelling, applications. Natural Hazards and Earth System Sciences, 14 (5), 1361.

van Staalduinen, M. A., Khan, F., \& Gadag, V. (2016). SVAPP methodology: A predictive security vulnerability assessment modeling method. Journal of Loss Prevention in the Process Industries, 43 , 397-413.

Zhang, L., Xu, Y., Liu, Y., \& Peng, M. (2013). Assessment of flood risks in Pearl River Delta due to levee breaching. Georisk: Assessment and Management of Risk for Engineered Systems and Geohazards, 7 (2), $122-133$.

Zhou, Z., Wang, X., Sun, R., Ao, X., Sun, X., \& Song, M. (2014). Study of the comprehensive risk analysis of dam-break flooding based on the numerical simulation of flood routing. Part II: Model application and results. Natural Hazards, 72 (2), 675. 